\title{
Ultrastructural visualization of the transmembranous and cytomatrix-related part of nicotinic acetylcholine receptor of frog motor endplate by means of an immunochemical avidity of IgG for d-tubocurarine
}

\author{
Keiji Hirai $^{1}$, Yoshifumi Katayama1 ${ }^{1}$, Gabriel Peltre ${ }^{2}$, Shigeru Tsuji ${ }^{3}$ \\ ${ }^{1}$ Department of Autonomic Physiology, Medical Research Institute, Tokyo Medical and Dental University, \\ Tokyo \\ ${ }^{2}$ Laboratoire Allergie et Environnement, LECA, Ecole Supérieure de Physique et Chimie Industrielles, Paris \\ ${ }^{3}$ Departement de Cytologie, Université Pierre et Marie Curie, Paris, France
}

\begin{abstract}
In the present study, a fine ultrastructural localization of nicotinic acetylcholine receptor (nAChR) was attempted, using d-tubocurarine (d-TC), a quaternary ammonium compound binding to nAChR. The localization was based on the binding avidity of immunoglobulin $\mathrm{G}(\mathrm{IgG})$ for acetylcholine ( $\mathrm{ACh}$ ) and other quaternary ammonium compounds, such as d-TC. d-TC was applied to the frog neuromuscular preparation and caused a blockade of neuromuscular transmission. Then, d-TC was rendered insoluble in situ by silicotungstic acid (STA), a precipitating agent of soluble proteins and quaternary ammonium compounds. After tissue fixation, a normal rabbit serum was applied to the fine precipitate of the insoluble salt of d-TC silicotungstate (quaternary ammonium radical of d-TC) to form the immunochemical complex d-TC-rabbit IgG at ACh binding sites. The IgG of the complex was revealed by means of the conventional immunoperoxidase procedure used for ultrastructural localization. Under the electron microscope, fine diaminobenzidine (DAB) precipitates appeared as regular rod-like structures oriented to cytoplasmic side of the horizontal part (crest) of the postsynaptic membrane (between the junctional folds) which is known to be endowed with nAChR. The rod-like precipitates were not observed in the postsynaptic junctional folds which are devoid of nAChR. The distance separating the rods each other was rather constant (12 $15 \mathrm{~nm}$ ), while the length of the rods was variable and exceeded the usual length of $\mathrm{nAChR}$. The present work indicates that the rod-like structures, already observed in association with sarcoplasmic side of the postsynaptic membrane, did correspond to the intramembranous and intracytoplasmic part of $\mathrm{nAChR}$ and related proteins. These cytochemical results confirm that $\mathrm{d}-\mathrm{TC}$ binds to ACh binding sites in the pore of $\mathrm{nAChR}$, and raise the question of DAB staining of cytoskeletal proteins related to the nAChR complex.
\end{abstract}

Keywords: Immunoglobulin - Quaternary ammonium compound - d-tubocurarine - Nicotinic acetylcholine receptor - Silicotungstic acid - Immunoperoxidase

\section{Introduction}

Bernard [1] was the first physiologist who observed that curare (d-tubocurarine: d-TC) was a blocking agent of the neuromuscular transmission. Langley [2] deduced from experimental data that curare reacted with "a receptive substance" (nowadays identified as nicotinic acetylcholine receptor, $\mathrm{nAChR}$ ) on the mus-

Correspondence: S. Tsuji, Dept. of Cytology, University Pierre \& Marie Curie, 7 Quai Saint Bernard, 75005-Paris, France; 13 rue des Benards, 92220-Bagneux, France; tel./fax.: $(+331)$ 46550427, e-mail shgrtsuji@wanadoo.fr cle side. It was demonstrated that d-TC binds, competitively with $\mathrm{ACh}$, to $\mathrm{nAChR}$ of the postsynaptic membrane [3-5].

The nAChR protein was characterized, for the first time, by Changeux et al. [6] after its isolation from the electric organ of the electric eel (a homologous organ of skeletal muscle) by means of $\alpha$-bungarotoxin, a specific snake neurotoxin. Today, nAChR is one of the most studied ligand-gated channels of fast chemical synapses [7].

In the electric organ, nAChR was localized at optical microscopic level on the postsynaptic membranous area by autoradioautography with radioactive curare 
compounds [8] and by immunofluorescence with snake naja $\alpha$-toxine [9] or with fluorescent dye conjugated $\alpha$-bungarotoxin [10]. At the electron microscopic level, nAChR was localized by autoradiography using radioactive $\alpha$-bungarotoxin [11-17] and by immunoperoxidase visualization of $\alpha$-bungarotoxin bound to nAChR [18]. However, limited resolving power of autoradiography and diffusion of diaminobenzidine $(\mathrm{DAB})$ precipitates in the synaptic cleft did not provide localization of $\mathrm{nAChR}$ at molecular level. By means of conventional electron microscopic technique $[19,20]$ and cryoultramicrotomy [21], comb-like structures were observed protruding in the synaptic cleft. These structures were interpreted as visualization of arrays of the external parts of $\mathrm{AAChR}$ molecules. Freeze etching technique applied on the Torpedo electroplaque provided clusters of crystallike nAChR molecules [22-24] and negative staining gave an oligomeric molecular form with central pore [25-27]. Outline of nAChR molecules attached to postsynaptic membrane fragments of Torpedo electroplaque was visualized by high resolution cryo-electron microscopy [28]. These studies, and the following ones, revealed that nAChR was composed of an extracellular pentameric subunit with a central pore toward the synaptic cleft, of an intramembranous part with the gate at open and closed state, of a cytoplasmic part endowed with openings in the channel wall in the subsynaptic sarcoplasm, and of proteins associated to the cytoplasmic side of nAChR [29-33].

In this work, an ultrastructural localization of d-TC bound to nAChR was performed by means of conventional immunoperoxidase procedure. The present method is based on the recently discovered avidity of $\mathrm{IgG}$ for quaternary ammonium compounds, such as ACh and d-TC [34]. The immunoperoxidase staining showed regularly disposed rod-like structures, probably corresponding to the pores of $\mathrm{nAChR}$, oriented not to the synaptic cleft but to the cytoplasmic side of the postsynaptic membrane. Since the rod-like structure penetrates deeply in the subneural sarcoplasm and exceeds largely the length of nAChR, its relationship with fibrous structure in the subsynaptic sarcoplasm [35-38] was discussed.

\section{Materials and methods}

Frog cutaneous pectoris muscles were taken out with the motor nerve bundles and pinned on the bottom of an experimental chamber containing $5 \mathrm{ml}$ of Ringer solution $(112 \mathrm{mM} \mathrm{NaCl}, 2.0 \mathrm{mM}$ $\mathrm{KCl}$ and $1.8 \mathrm{mM} \mathrm{CaCl}_{2}$ ). Ringer solution was buffered with 25 $\mathrm{mM}$ Tris(hydroxymethyl)aminomethane - $\mathrm{HCl}$ (Tris-HCl) buffer solution at $\mathrm{pH}=7.8$.

The bundle of motor nerves was stimulated electrically with a pair of silver chloride electrodes (supramaximal voltage: 3-7 V, during $0.3 \mathrm{~ms}$ ) at $0.3 \mathrm{~Hz}$ and the muscle contractions were monitored on a chart recorder (San-ei, Tokyo, Japan; Recti-Horiz) by isometric mechano-electric transducer (Nihon Koden, Tokyo,

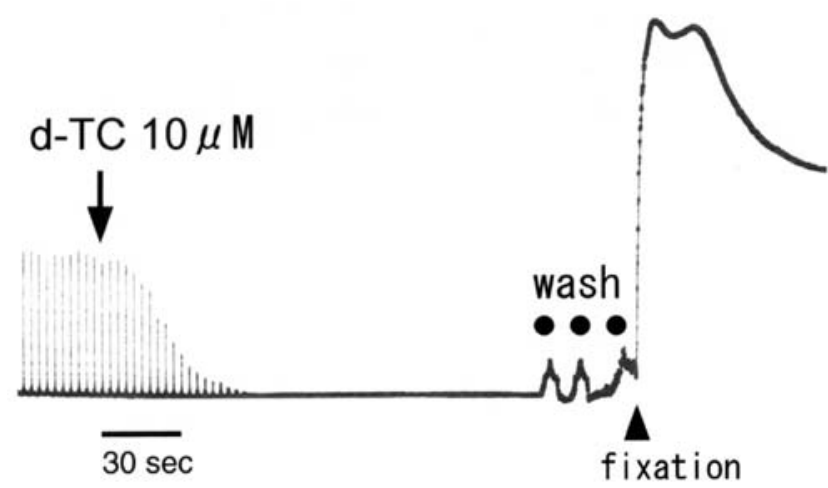

Fig. 1. Blockade of the neuromuscular transmission with $10 \mu \mathrm{M} \mathrm{d}$ TC. The neuromuscular preparation (frog cutaneous pectoralis muscle) under submaximal electrical stimulation of the motor nerve. Synaptic transmission was blocked within $1 \mathrm{~min}$, and the preparation remained in contact with d-TC for two additional min. After three rapid washes in single Ringer solution, the preparation was fixed with $5 \%$ aqueous solution of silicotungstic acid (STA).

Japan; TB-611T). Peak tension of control muscular twitch due to nerve stimulation was approximately $3 \mathrm{~g}$.

$10^{-5} \mathrm{M}$ d-tubocurarine (d-TC) was applied to the preparation. The subsequent blockade of neuromuscular transmission was monitored and confirmed by submaximal electrical stimulation of the motor nerve after 3 min (Fig. 1). After a rapid wash (30 s) of the preparation with Ringer solution without buffer (simple Ringer), the preparation was fixed in $5 \%$ aqueous solution of silicotungstic acid (STA) for $15 \mathrm{~min}$. The tissue was washed three times in the simple Ringer solution for $3 \mathrm{~min}$, and fixed for $12 \mathrm{~h}$ with $3.7 \%$ formalin dissolved in the simple Ringer. Then, the preparation was washed in the simple Ringer for $3 \mathrm{~min}$, and in two bathes of a phosphate buffered saline (PBS: $120 \mathrm{mM} \mathrm{NaCl}$ with $0.01 \mathrm{M}$ sodium phosphate buffer at $\mathrm{pH}=7.4$ ) for $2 \times 3 \mathrm{~min}$. The binding of $\mathrm{IgG}$ to d-TC silicotungstate precipitate, based on the avidity of IgG for ammonium quaternary compounds, was performed as presently described: The preparation was treated with the following immunochemical agents dissolved in PBS: $1 \%$ bovine serum albu$\min$ (Biosis) (30 $\mathrm{min}), 1 \%$ rabbit normal serum (3h), washing in PBS ( $3 \times 5$ min), 1/500 diluted Anti-Rabbit IgG (whole molecule)peroxidase (Sigma, USA) (2h), washing in PBS ( $3 \times 5 \mathrm{~min}$ ), $0.02 \%$ diaminobenzidine tetrahydrochloride (DAB) and $0.01 \% \mathrm{H}_{2} \mathrm{O}_{2}(20$ $\mathrm{min})$. After washing in PBS, the preparation was postfixed in $2 \%$ aqueous solution of $\mathrm{OsO}_{4}(30 \mathrm{~min})$, washed in water, dehydrated in graded series of ethanol solutions and embedded in Araldite. Ultrathin sections were observed without counterstaining under JEOL $100 \mathrm{CX}$ electron microscope at $80 \mathrm{kV}$. As control experiment of d-TC reaction, the experimental procedure described above was performed without d-TC blockade of the neuromuscular junction.

\section{Results}

After blockade of the neuromuscular junction with dtubocurarine (d-TC), precipitation of d-TC with silicotungstic acid (STA), and postfixation of the tissue with formalin, the conventional indirect immunoperoxidase reaction revealed the presence of rabbit IgG that bound to d-TC precipitated in the vicinity of its binding site with nAChR. At the electron microscopic level, diaminobenzidine (DAB) staining was observed at the 


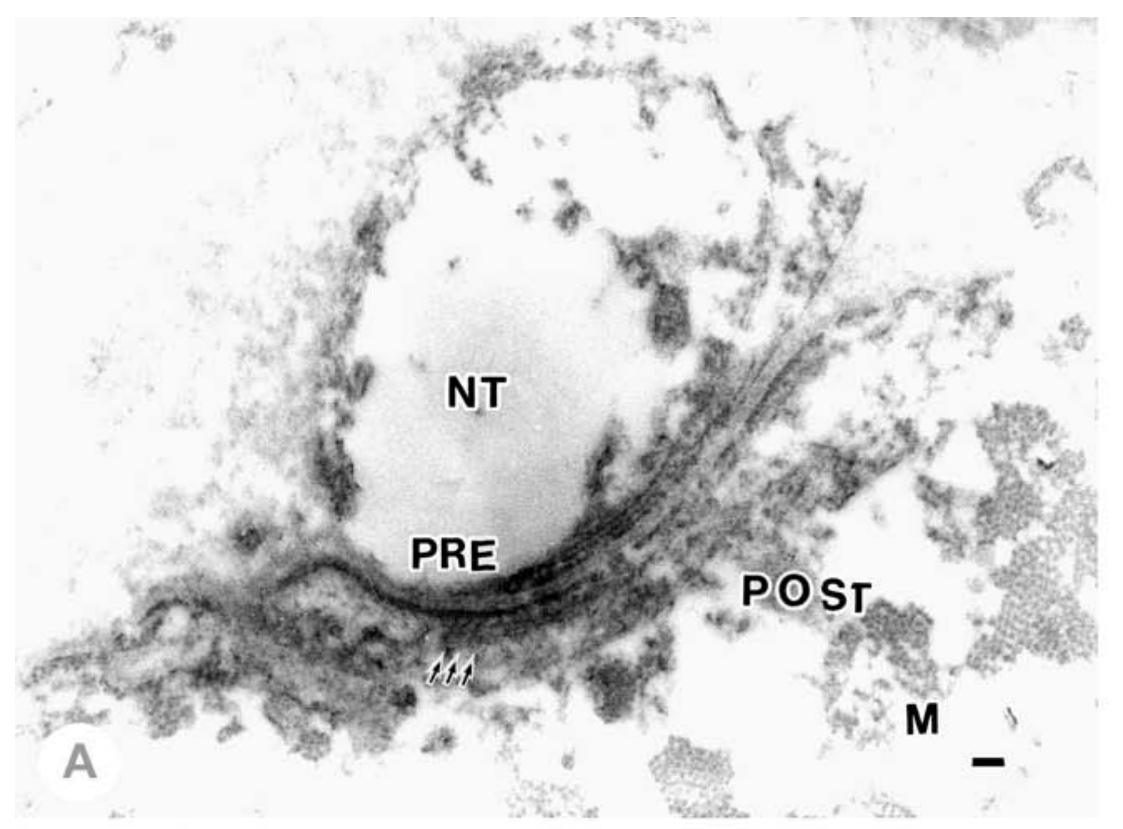

Fig. 2. Electron microscopic observation of frog neuromuscular junction after the following treatments: blockade of the synaptic transmission with d-TC, insolubilization of d-TC by STA and fixation of tissues by formalin, binding of rabbit IgG with the in situ insolubilized d-TC, and staining of the IgG by immunoperoxidase procedure. Rod-like structures are observed in regular arrays crossing the postsynaptic membrane and deeply penetrating into the subsynaptic sarcoplasm (arrows). The rod-like structures do

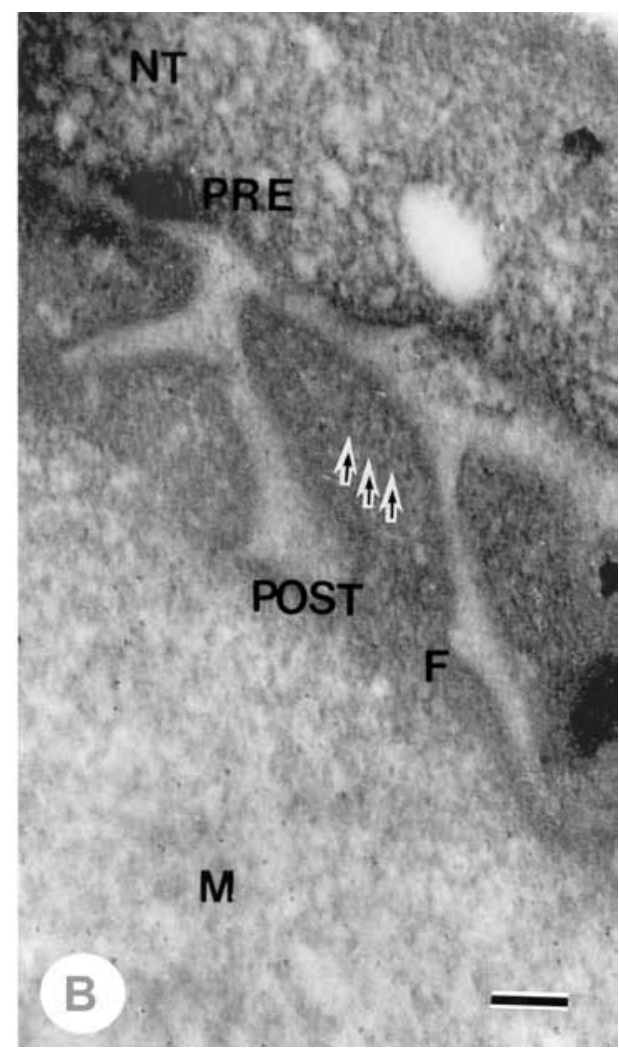
not protrude in the synaptic cleft. Transversal (A) and longitudinal section (B) of the muscle fibers. NT: Nerve terminal, PRE: presynaptic membrane, POST: postsynaptic membrane, M: muscle cell, F: folding of the postsynaptic membrane. Bar $100 \mathrm{~nm}$.

horizontal part (crest) of the postsynaptic membrane (Fig. 2A). The perpendicular junctional folds including the bottom of the postsynaptic membrane (trough) were devoid of staining (Fig. 2B). At closer observation, the postsynaptic membrane stained with $D A B$ reveals transmembranous rod-like structures separated each other by a distance of $12-15 \mathrm{~nm}$. These transmembranous rod-like structures were not oriented to the synaptic cleft but crossed the membrane and penetrated deeply into the cytoplasm (Fig. 2A and B: arrows). The length of the rods was variable (25-100 $\mathrm{nm}$ ) and largely overpassed the length of nicotinic acetylcholine receptor (nAChR).

Control neuromuscular preparation, without d-TC, revealed a moderate staining, weaker than in the experiment including d-TC. (Fig. 3: arrowhead).

\section{Discussion}

The rod-like structures stained by diaminobenzidine (DAB) in the postsynaptic membrane area of the neuromuscular junction probably correspond to arrays of nicotinic acetylcholine receptor (nAChR). Indeed, dtubocurarine (d-TC) dropped on a nitrocellulose membrane has been shown to be a good target of the avidity of IgG molecules after its precipitation by silicotungstic acid (STA) [34]. In this experimental model, an intense staining was obtained after immunoperoxi- dase reaction performed on d-TC-STA complex. Therefore, in the present study, the staining associated with the rod-like structures is presumably due to $\operatorname{IgG}$ bound to d-TC-STA complex and visualized by immunoperoxidase procedure in the pore of $n A C h R$. Thus, the present work confirms pharmacological binding of d-TC to the nAChR of frog endplate. Furthermore, it provides complementary data to previous ultrastructural localizations of nAChR. Indeed, immunoperoxidase reaction for bungarotoxine gave diffuse DAB precipitates in the synaptic cleft [18] and autoradiography with radioactive neurotoxine provided intense and quantifiable signal, nevertheless not appropriate to a fine localization of neurotoxine bound structures [17].

The weak persistence of the reaction in the control experiment without d-TC was not expected. It might be due to the endogenous acetylcholine (ACh) fixed into the nAChR by STA and bound to IgG. Indeed, it was shown that IgG could bind ACh precipitated with STA on a nitrocellulose membrane [34].

The stained rod-like structures were oriented into the cytoplasmic side of the postsynaptic membrane, and did not extend in the synaptic cleft. These rods were separated each other by a rather regular space of about 12-15 nm, which corresponds to the conventional electron microscopic observations of the part of nAChR oriented to the synaptic cleft [19-21]. 


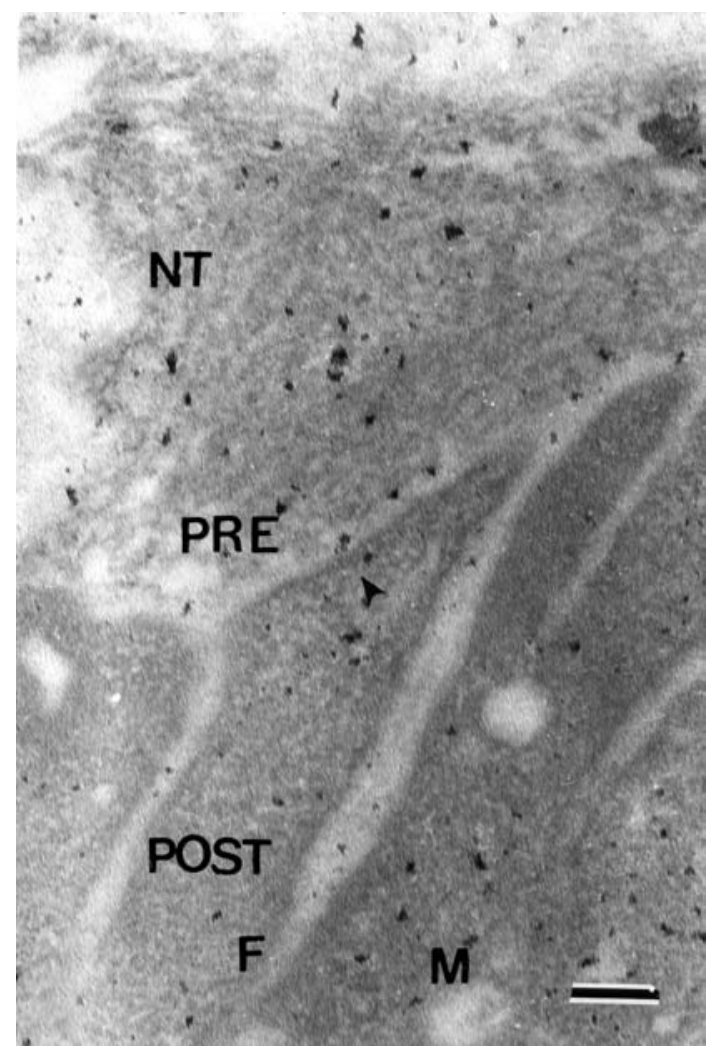

Fig. 3. A control tissue without d-TC treatment is not completely immuno-negative and reveals moderately stained transmembranous rod-like structures (arrowhead). The persistence of the reaction is presumed to be derived from the endogenous ACh rendered insoluble by STA inside the $\mathrm{nAChR}$ and bound to IgG. Longitudinal section of the muscle fiber. NT: Nerve terminal, PRE: presynaptic membrane, POST: postsynaptic membrane, M: muscle cell, F: folding of postsynaptic membrane. Bar $100 \mathrm{~nm}$.

Precedent authors studied the ultrastructure of the neuromuscular junction with conventional cytological methods. They noticed a particular density of the postsynaptic membrane on the subneural sarcoplasm [39]. The exact thickness of this dense part of the postsynaptic membrane was hindered by "fringes" attached to the sarcoplasmic side of the postsynaptic membrane $[35,36]$. A close observation of the fringes reveals, though shorter in length, nothing but the rod-like structures stained by d-TC in the present work. In a similar study on subsynaptic sarcoplasm of mammalian neuromuscular junction, a cortical network associated by a lattice to the postsynaptic membrane was shown [37]. This lattice partially corresponds to the rod-like structures evidenced in the present study. In an ultrastructural image of frog neuromuscular junction obtained after cryosubstitution [40], a similar rod-like structure oriented to cytoplasmic side of the postsynaptic membrane was seen. At the end, after chemical washing, a submembranous meshwork was observed just beneath the postsynaptic membrane of the neuromuscular junction [41]. Thus, these authors have pro- vided figures corresponding to the rod-like structure that was identified, in the present work, as cytoplasmic part of nAChR.

The rod-like structures penetrated through postsynaptic membrane and entered into the cytoplasm at variable depth (25-100 nm), which overpassed the length of $\mathrm{nAChR}(16 \mathrm{~nm})$ [33]. This pattern of staining may correspond to the filamentous structures bound to the cytoplasmic side of nAChR [37,38,42]. Indeed, a 43-kD protein is supposed to be connected to the cytoplasmic side of nAChR molecule, $[29,43,44]$. This protein was identified as an acetylcholine receptor-associated-protein (RAPsyn) [30] which has a role of clustering nAChR [45]. More recently, cryoelectron microscopic technique, applied on reconstituted postsynaptic membrane of Torpedo electric organ, has shown the cytoplasmic side of nAChR, including cytoplasmic mass and attached protein [31-33]. It is probable that RAPsyn and a part of cytoskeleton connected to the nAChR $[46,47]$ have been stained by DAB in the present work.

Why the rod-like structures stained by $\mathrm{DAB}$ deeply extended in the sarcoplasm remains an unsolved question. d-TC is assumed to be bound to ACh binding sites [5] which are situated inside nAChR about halfway between the extracellular ends of the $\alpha$-subunits and the membrane [31,33]. Since IgG is supposed to be bound to d-TC, DAB, the reaction product of immunoperoxidase, can diffuse in the pore of the channel both toward the synaptic cleft and the sarcoplasmic side. The staining of the cytoplasmic part of $n A C h R$ and related proteins suggests that the channel pore remained open in the present experimental conditions. The synaptic cleft, which is an extracellular space, is voluminous and rich in free water [48]. Thus, it does not provide a good condition for the precipitation of DAB. On the contrary, the pore, though also being an extracellular space, is incomparably less voluminous than the synaptic space and, so, much more favourable for precipitation of DAB. After staining inside the pore of the transmembranous nAChR, DAB might come out the pore through the openings in the channel wall, enter into the cytoplasm $[31,33]$ and stain the fibrous structure connected to $\mathrm{nAChR}$.

An other question is why a so small quantity of $\mathrm{DAB}$ has not been diluted in the cytosol after its penetration through the pore? To answer this enigma it is of interest to recall that the cytosol is considered rather as a cytogel, a structured cytomatrix [49], where free water is much less abundant than in the extracellular space [48]. In that case, even after cytological fixation, the cytomatrix might hinder diffusion of $\mathrm{DAB}$ and favor its precipitation on the surface of the fibrous structures. Further studies are necessary to verify these interpretations concerning the DAB staining of different subsynaptic fibrous structures. 
Acknowledgments: The authors thank Mrs. M. J. Brisorgeil for her technical assistance, Dr. S. Ichinose for facilities of electron microscopic observation and Dr. P. Anglad for his critical reading and English correction of the manuscript. This work was supported by CNRS (France) and Grant-in-Aid for Scientific Research (KAKENHI, 14570912 in Japan).

\section{References}

[1] Bernard C. Analyse physiologique des propriétés des systčmes musculaires et nerveux au moyen du curare. CR Acad Sci. 1856;43:825-829.

[2] Langley JN. On nerve endings, and on special excitable substances in cells. Proc RS. 1906;78B:170-194.

[3] Jenkinson DH. The antagonism between tubocurarine and substances which depolarize the motor end plate. $J$ Physiol. (Lond) 1960;152:309-324.

[ 4] Neubig RR, Cohen JB. Equilibre binding of [3H]tubocurarine and $[3 \mathrm{H}]$ acetylcholine by Torpedo postsynaptic membranes: stoichiometry and ligand interactions. Biochem. 1979;18: 5464-5475.

[5] Pedersen SE, Cohen JB. $d$-Tubocurarine binding sites are located at $\alpha-\gamma$ and $\alpha-\delta$ subunit interfaces of the nicotinic acetylcholine receptor. Proc Natl Acad Sci USA. 1990;87: 2785-2789.

[ 6] Changeux JP, Kasai M, Lee CY. Use of snake venom toxin to characterize the cholinergic receptor protein. Proc Natl Acad Sci. 1970;67:1241-1247.

[7] Hille B. Ion channels of excitable membranes. 3rd Ed. Sinauer, Sunderland, MA, USA. 2001.

[ 8] Waser PG. On receptors in the postsynaptic membrane of the motor endplate. In: Porter, R. and O'connor, M. (Eds., Molecular properties of drog receptors. J. \& A. Churchill, London), 1970;59-75.

[ 9] Bourgeois JP, Tsuji S, Boquet P, Pillot J, Ryter A, Changeux JP. Localization of the cholinergic receptor protein by immunofluorescence in eel electroplax. FEBS Letters. 1971; 16:92-94

[10] Anderson MJ, Cohen MW. Fluorescent staining of acetylcholine receptors in vertebrate skeletal muscle. $J$ Physiol. 1974;237:385-400.

[11] Albuquerque EX, Barnard EA, Porter CW, Warnick JE. The density of acetylcholine receptors and their sensitivity in the postsynaptic membrane of muscle endplates. Proc Nat Acad Sci USA. 1974;71:2818-22.

[12] Bourgeois JP, Popot JL, Ryter A, Changeux JP. Consequences of denervation on the distribution of the cholinergic (nicotinic) receptor sites from Electrophorus electricus revealed by high resolution autoradiography. Brain Res. 1973;62:557-563

[13] Fertuck HC, Salpeter MM. Quantitation of junctional and extrajunctional acetylcholine receptors by electron microscope autoradiography after ${ }^{125} \mathrm{I}-\alpha$-bungarotoxin binding at mouse neuromuscular junctions. J Cell Biol. 1976;69:144-158.

[14] Matthews-Bellinger J, Salpeter MM. Distribution of acetylcholine receptors at frog neuromuscular junctions with a discussion of some physiological implications. J Physiol. 1978; 279:197-213

[15] Peper K, McMahan UJ. Distribution of acetylcholine receptors in the vicinity of nerve terminals on skeletal muscle of the frog. Proc Royal Soc Lond B. 1972;181:431-440.

[16] Porter CW, Barnard EA. The density of cholinergic receptors at the endplate postsynaptic membrane: ultrastructural studies in two mammalian species. J Membrane Biol. 1975;20:31-49.

[17] Salpeter MM. Vertebrate neuromuscular junctions: General morphology, molecular organization, and functional consequences. In Neurology and Neurobiology Volume 23 (Ed. Salpeter, M. M.) Alan R. Liss, Inc., New York, 1987.
[18] Daniels MP, Vogel Z. Immunoperoxidase staining of $\alpha$-bungarotoxin binding sites in muscle endplates shows distribution of acetylcholine receptors. Nature. 1975;254:339-341.

[19] Rosenbluth J. Substructure of amphibian motor end plate. Evidence for a granular component projecting from the outer surface of the receptive membrane. J Cell Biol. 1974; 62:755-766.

[20] Rosenbluth J. Synaptic membrane structure in Torpedo electric organ. J Neurocytol. 1975;4:697-712.

[21] Tsuji S. Ultracryotomy of nerve-electrique synapses for immunocytochemistry. J Neurocytol. 1978;7:381-389.

[22] Dreyer F, Peper K, Akert K, Sandri C, Moor H. Ultrastructure of the "active zone" in the frog neuromuscular junction. Brain Res. 1973;62:373-80.

[23] Peper K, Dreyer F, Sandri C, Akert K, Moor H. Structure and ultrastructure of the frog motor endplate. A freeze-eching study. Cell Tissue Res. 1974;149:437-455.

[24] Rash JE, Ellisman MH. Studies of excitable membranes. I. Macromelecular specializations of the neuromuscular junction and the non-junctional sarcolemma. J Cell Biol. 1974;63: 567-568.

[25] Cartaud J, Benedetti EL, Cohen JB, Meunier JC, Changeux JP. Presence of a lattice structure in membrane fragments rich in nicotinic receptor protein from the electric organ of Torpedo marmorata. FEBS Lett. 1973;33:109-113.

[26] Cartaud J, Benedetti EL, Sobel A, Changeux JP. A morphological study of the cholinergic receptor protein from Torpedo Marmorata in its membrane environment and in its detergent-extracted purified form. J Cell Sci. 1978;29: 313-337.

[27] Nickel E, Potter LT. Ultrastructure of isolated membranes of Torpedo electric tissue. Brain Res. 1973;57:508-517.

[28] Toyoshima C, Unwin, N. Ion channel of acetylcholine receptor reconstructed from images of postsynaptic membranes. Nature. 1988;336:247-250.

[29] Sealock R, Wray BE, Froehner C. Ultrastructural localization of the $\mathrm{Mr} 43,000$ protein and the acetycholine receptor in Torpedo postsynaptic membranes using monoclonal antibodies. J Cell Biol. 1984;98:2239-2244.

[30] Frail DE, McLaughlin LL, Mudd J, Merlie JP. Identification of the mouse muscle 43,000-dalton acetylcholine receptorassociated protein (RAPsyn) by cDNA cloning. J Biol Chem. 1988;263:15602-15607.

[31] Miyazawa A, Fujiyoshi Y, Stowell M, Unwin N. Nicotinic acetylcholine receptor at $4.6 \mathrm{~A}$ resolution: Transverse tunnels in the channel wall. J Mol Biol. 1999;288:765-786.

[32] Unwin N. Nicotinic acetylcholine receptor at 9 Ĺ resolution. J Mol Biol. 1993;229:1101-1124.

[33] Unwin N. The Croonian Lecture 2000. Nicotinic acetylcholine receptor and the structural basis of fast synaptic transmission. Phil Trans R Soc Lond B Biol Sci. 2000;355:18131829.

[34] Tsuji S, Tooyama I, Kato T, Peltre G, Kimura H. Binding avidity of immunoglobulin $\mathrm{G}$ for acetylcholine. Biomed Res. 2003;24:217-221.

[35] Couteaux R. Structure of the subsynaptic sarcoplasm in the interfolds of the frog neuromuscular junction. J Neurocytol. 1981;10:947-962

[36] Couteaux R, Pécot-Dechavassine M. Particularités structurales du sarcoplasme sous-neural. C R Acad Sci. 1968;266:8-10.

[37] Ellisman MH, Rash JE, Staehelin A, Porter KR. Studies of excitable membranes. II. A comparison of specializations at neuromuscular junctions and nonjunctional sarcolemmas of mammalian fast and slow twitch muscle fibers. J Cell Biol. 1976;68:752-774.

[38] Heuser JE, Salpeter, SR. Organization of acetylcholine receptors in quick-frozen, deep-etched, and rotary-replicated Torpedo postsynaptic membrane. J Cell Biol. 1979;82:150-173. 
[39] Birks R, Huxley HE, Katz B. The fine structure of the neuromuscular junction of the frog. J Physiol (Lond). 1960;150: 134-144.

[40] Heuser JE. 3-D visualization of membrane and cytoplasmic specializations of the frog neuromuscular junction. In: Ontogenesis and Functional Mechanisms of Peripheral Synapses (edited by Taxi, J.) pp. 139-55. INSERM Symposium no. 13. Amsterdam, Elsevier/North-Holland. 1980.

[41] Hirokawa N, Heuser JE. Internal and external differentiations of the postsynaptic membrane at the neuromuscular junction. J Neurocytol. 1982;11:487-510.

[42] Cartaud J, Sobel A, Rousselet A, Devaux PF, Changeux JP. Consequence of alkaline treatment for the ultrastructure of the acetylcholine-receptor-rich membranes from Torpedo marmorata electric organ. J Cell Biol. 1981;90:418-426.

[43] Bridgman PC, Carr C, Pederson SE, Cohen JB. Visualization of the cytoplasmic surface of Torpedo postsynaptic membranes by freeze-etch and immunoelectron microscopy. J Cell Biol. 1987;105:1829-1846.
[44] Walker JH, Boustead CM, Witzermann V. The 43-K protein, $v_{1}$, associated with acetylcholine receptor containing membrane fragments is an actin-binding protein. EMBO J. 1984;3: 2287-2290

[45] Froehner SC, Luetje CW, Scotland PB, Patrick J. The postsynaptic $43 \mathrm{~K}$ protein clusters muscle nicotinic acetylcholine receptors in Xenopus oocytes. Neuron 1990;5:403-410.

[46] Colledge M, Froehner SC. Signals mediating ion channel clustering at the neuromuscular junction. Cur Opin Neurobiol. $1998 ; 8: 357-363$

[47] Whatley VJ, Harris A. The cytoskeleton and neurotransmitter receptor. Internat Rev Neurobiol. 1996;39:113-143.

[48] Mentré P. L'eau dans la cellule. Une interface hétérogčne et dynamique des macromolécules. Masson, Paris. 1996. (Japanese translation as "Saibo no naka no mizu" by S. Tsuji, S. Nakanishi, M. Ochiai and T. Ohoka: University of Tokyo Press, 2006).

[49] Porter KR. The cytomatrix: A short history of its study. J Cell Biol. 1984;99:3s-12s.

Submitted: 30 June, 2007 Accepted after reviews: 2 September, 2007 
